\title{
Influence of L-arginine on expression of HSP70 and p-53 proteins - early biomarkers of cellular danger in renal tubular cells. Immunohistochemical assessment
}

\author{
Agnieszka Pedrycz ${ }^{1}$, Piotr Siermontowski
}

1Department of Histology and Embryology, Medical University of Lublin, Poland 2 Maritime and Hyperbaric Medicine Department, Military Medicine Institute, Gdynia, Poland

Submitted: 16 January 2012

Accepted: 23 July 2012

Arch Med Sci 2013; 9, 4: 719-723

DOI: 10.5114 /aoms.2013.37273

Copyright $\odot 2013$ Termedia \& Banach

\author{
Corresponding author: \\ Prof. Agnieszka Pedrycz \\ Department of Histology \\ and Embryology \\ Medical University of Lublin \\ $5 / 34$ Leonarda St \\ 20-625 Lublin, Poland \\ Phone: +48 517259103 \\ E-mail: apw4@wp.pl
}

\begin{abstract}
Introduction: The aim of the present study was to investigate expression of HSP70 and $\mathrm{p}-53$ proteins as mechanisms of protection of the renal tubular epithelial cells from l-arginine that induces cellular stress.

Material and methods: The study material consisted of 16 white Wistar female rats. The rats were divided into 2 equal groups. The rats in the experimental group received L-arginine $40 \mathrm{mg} / \mathrm{kg}$ body weight per capita every other day for 2 weeks and were decapitated after 3 weeks of the experiment. After decapitation, specimens from the kidney were collected, fixed in $10 \%$ formalin, and then embedded in paraffin blocks. Proteins HSP70 and p-53 on slides were detected using the standard three-step immunohistochemical method.

Results: The quantitative evaluation of HSP70 and p-53 expression showed that the area occupied with positive HSP70 and p-53 reaction in the rat renal tubular cells of the experimental group (p-53: $2835.44 \pm 254.72 \mu \mathrm{m}^{2}$; HSP70: 24111.42 $\pm 4290.88 \mu \mathrm{m}^{2}$ ) was more statistically significant than the control group (p-53: $1882.05 \pm 466.43 \mu \mathrm{m}^{2}$; HSP70: $11388.63 \pm 1455.24 \mu \mathrm{m}^{2}$ ). In the present study, the dose of L-arginine was similar to the one that was used in the gestosis treatment of pregnant women.

Conclusions: The renal epithelial cells responded to L-arginine therapy, increasing expression of HSP70 and p-53 proteins. The study showed that L-arginine as a donor of exogenous nitric oxide has a disruptive effect on the renal tubular cells of rat kidneys. Thus it is going to be a subject of the author's future investigations.
\end{abstract}

Key words: HSP70, p-53, L-arginine, kidney, immunohistochemistry.

\section{Introduction}

The author of the previous study noticed that L-arginine decreased the level of HSP70 expression in kidney cells of the rat fetuses during Adriamycin apoptosis [1].

Other studies, conducted by the author, examined rat hepatocytes after L-arginine therapy [2]. The study showed that L-arginine as a donor of exogenous nitric oxide did not have an apoptotic effect on the hepatocytes of the rats.

In the present study, the author wanted to check the influence of L-arginine on the expression of two early cellular stress biomarkers (HSP70 and $\mathrm{p}-53$ proteins) in renal tubular cells [3]. 
$\mathrm{P}-53$ is a protein that is activated in the cell by damaged DNA. P-53 can activate apoptosis by inducing protein 1 (AIP1) in cells which will undergo it [4]. This protein associates with the mitochondria and releases molecules inducing caspase [5]. The cell produces AIP1 several hours after DNA damage, which makes it impossible to repair the damaged genetic material.

Heat shock proteins (HSP) have been known since the mid-1980s as proteins that were observed in bacteria that were exposed to temperatures $4-5^{\circ} \mathrm{C}$ higher than normal. In the 1980s, Żylicz discovered some more functions of these proteins [6]. He called them protective proteins, which regulate many basic life processes of cells, and concentrated on the prevention of effects of the harmful factors [7].

The functions of chaperones include formation of the proteins' spatial structure, binding the protein sub-units into oligomers and assisting in proteins' transport through the organelle membranes. It helps to prevent the abnormal formation of nonfunctional protein structures. The expression of genes encoding HSPs is induced by so-called environmental stress [8].

The aim of the present study is to investigate overexpression of HSP70 and $\mathrm{p}-53$ proteins as mechanisms for protecting the renal tubular epithelial cells against l-arginine-induced cellular stress.

\section{Material and methods}

The material for the study consisted of 16 white Wistar female rats with a baseline body weight of 200-250 g aged 3.5-4 months. Due to the simultaneity principle, the rats were randomly assigned to the control and experimental group.

The animals received standard feed and water ad libitum. The rats were divided into 2 equal groups of 8 females in each.

The rats in the experimental group received L-arginine through a stomach tube (Argininum, Curtis Healthcare, Poznan, Poland) in the amount of $40 \mathrm{mg} / \mathrm{kg}$ body weight $(5 \mathrm{mg}$ of L-arginine in $1 \mathrm{ml}$ of distilled water) 7 times every other day for 2 weeks.

The rats in the control group received $2 \mathrm{ml}$ of distilled water through a stomach tube every other day for 2 weeks. Rats were decapitated 3 weeks after the experiment.

The study was approved by the Local Ethics Committee in Lublin attached to the Medical University of Lublin, Al. Racławickie 1, No. 551/2005.

The rat kidneys were collected for immunohistochemical investigations. The kidneys for immunohistochemical studies were fixed in 10\% formalin buffered in phosphate buffer $\mathrm{pH}$ 7.0, and after dehydration in ascending ethanols, cleared in xylene and embedded in paraffin. Microtome sections were cut at $5 \mu \mathrm{m}$ and then adhered to the siliconised slides.

To identify p-53 and HSP70 proteins, preparations from experimental and control groups were used. For each preparation, a negative control (a slide without primary antibody) was used.

The protein expression level was evaluated with a standard three-step immunohistochemical procedure, labelled streptavidin biotin (LSAB), using DakoCytomation kits in compliance with the manufacturer's instructions. Mouse p53 (diluted $1: 50$ ) (Lab Vision Corporation, Fremont, CA, USA), and rabbit HSP70 (diluted 1: 100 (Lab Vision)) antibodies were used as a primary antibody. Then a biotinylated secondary antibody was added, and followed by horseradish peroxidase conjugated with streptavidin (DakoCytomation; Glostrup, Denmark). At the site of immunolocalization of the primary antibodies, after adding a chromogen, AEC (DakoCytomation; Glostrup, Denmark), a reddish colour appeared. The coloured reaction occurred because streptavidin has a strong affinity to biotin.

The expression of all proteins was evaluated in preparations taken from 8 rats from the control group and 8 rats from the experimental group (two preparations from every individual for each of the antibodies; in total, for each antibody there were 16 control slides and 16 experimental slides). The slides were analyzed by means of a light microscope. The photographic documentation was performed with a CCD-IRIS Colour Video Camera (Sony) connected with a computer.

The analysis of the microscopic images at a magnification of $125 \times$, to assess the expression of the protein, was performed by means of the computer program analySIS®Pro 3.0 (Soft Imaging System, Munster, Germany). Three randomly selected standard microscope fields of $781193.35 \mu \mathrm{m}^{2}$ were assessed from each slide. The field of the sectioned surface of kidney specimens with positive reactions was measured. An intensive red was assessed by the computer as positive; red-pink or pink were not assumed as a positive result.

\section{Statistical analysis}

The results were analyzed statistically by means of an ANOVA test and a Student's $t$-test. The averages, standard deviations and the percentage of positive reactions in the examined tissue field were determined. The differences were considered as statistically significant when $p<0.05$.

\section{Results}

Qualitative evaluation showed focal p-53 reaction in each group. The colour reaction was observed in the cytoplasm of renal tubular epithelial cells. The positive cytoplasm staining was dark pink in 

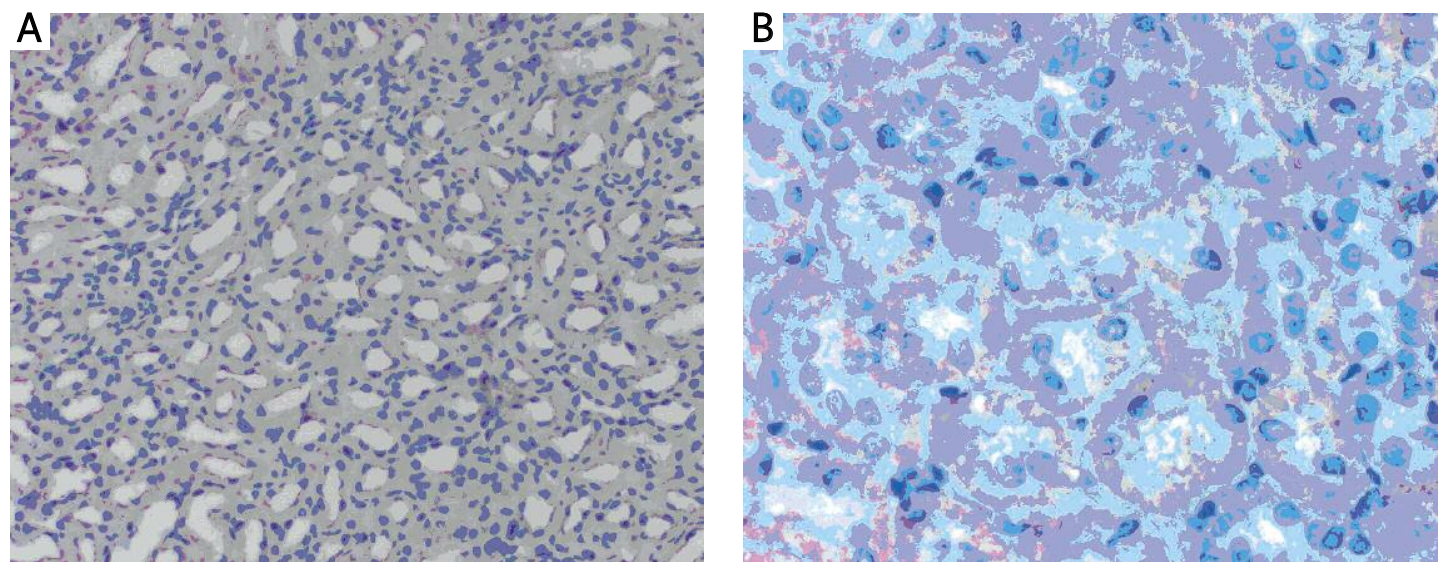

Figure 1. Immunohistochemical localization of p-53 protein in the kidney in (A) the control rats (weak cytoplasmic p-53 reaction), scale bar $=18 \mu \mathrm{m}$ and in (B) the experimental rats, decapitated after L-arginine administration ( $\mathrm{p}-53$ reaction of medium intensity), scale bar $=54 \mu \mathrm{m}$. All preparations stained with AEC (AEC Substrate chromogen) and nuclei counterstained with hematoxylin
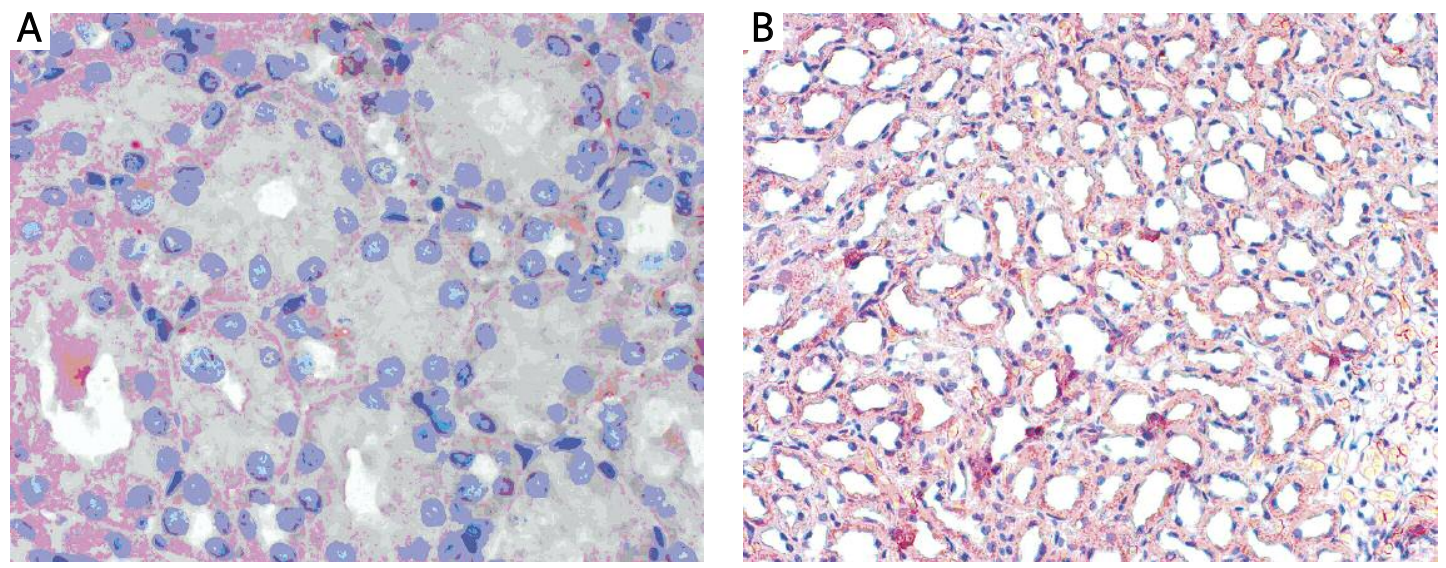

Figure 2. Immunohistochemical localization of HSP70 protein in the kidney in (A) the control rats (quite intensive cytoplasmic HSP70 reaction), scale bar $=54 \mu \mathrm{m}$, and in (B) the experimental rats, decapitated after L-arginine administration (HSP70 reaction of medium intensity), scale bar $=18 \mu \mathrm{m}$. All preparations stained with AEC (AEC Substrate chromogen) and nuclei counterstained with hematoxylin

both the control and the experimental group (Figures 1 A, B). The cytoplasm of the cells was stained at their bases in the vicinity of basilar membranes of renal tubular epithelial cells (Figure $1 \mathrm{~B}$ ). In the renal glomeruli, $\mathrm{p}-53(+)$ reaction was not observed.

The HSP70 reaction was visible focally in rat kidneys in both the experimental and the control group. The intensity of the reaction was comparable in the control and in the L-ARG group (Figures $2 \mathrm{~A}, \mathrm{~B})$. The colours ranged from bright to dark pink. The reaction filled the apical part of the cytoplasm of renal tubular epithelial cells.

Quantitative evaluation revealed the increased p-53 reaction that was observed in the L-arginine group in comparison to the control one (Table I). In the control group the mean area occupied with a positive, colour reaction was not too big (mean $0.24 \%$ of $781193 \mu \mathrm{m}^{2}$ field). Despite the fact that the increase in the experimental group was not
Table I. The mean area in $\mu \mathrm{m}^{2}$ occupied with a positive reaction of $p-53$ and HSP70 proteins in the standard fields of $781193 \mu \mathrm{m}^{2}$ in rat kidneys in both the control and the experimental group

\begin{tabular}{|lccc|}
\hline Protein & $\begin{array}{c}\text { Control } \\
\text { group } \\
\text { Mean } \pm \text { SD } \\
{\left[\mu \mathrm{m}^{2}\right]}\end{array}$ & $\begin{array}{c}\text { Experimental } \\
\text { group } \\
\text { Mean } \pm \text { SD } \\
{\left[\mu \mathrm{m}^{2}\right]}\end{array}$ & $\begin{array}{c}\text { Value of } \\
p^{*}\end{array}$ \\
\hline p-53 & 1882.05 & 2835.44 & 0.016 \\
& \pm 466.43 & \pm 254.72 & \\
\hline HSP70 & 11388.63 & 24111.42 & 0.005 \\
& \pm 1455.24 & \pm 4290.88 & \\
\hline
\end{tabular}

*One-way ANOVA test, statistical significance

large (mean $0.36 \%$ of $781193 \mu \mathrm{m}^{2}$ field), it was statistically significant $(p=0.016)$.

The HSP70 reaction was evaluated quantitatively by means of the computer programme, and it was quite strong in the control group (mean $1.5 \%$ of $781193 \mu \mathrm{m}^{2}$ field) (Table I). In the L-arginine group, 
we could only observe a slight increase (mean 3.0\% of $781193 \mu \mathrm{m}^{2}$ field). However, this increase was statistically significant $(p=0.005)$.

\section{Discussion}

In the present study the dose of L-arginine was similar to the one that was used in the gestosis treatment of pregnant women. This dose should be safe for a mother and a fetus [9].

In the organism, NO is produced from L-arginine with the aid of nitric oxide synthase (NOS), also called digoxygenase [10].

The effects of NO on cell damage are not fully known. It was demonstrated that the proapoptotic influence of NO was caused by oxidative stress which was induced in cells. The so-called "nitrosative stress" was described in the rat's macrophages, where NO-induced apoptosis was observed [11].

In the present study, after the exposure of renal cells to L-arginine, two mechanisms protecting cells against danger were initiated: the increase in HSP70 and in p-53 expression. It was a response of cells to oxidative stress - a result of $L$-arginine action.

HSP 70 belongs to the group of "molecular chaperones". Its increased concentration in the cytoplasm is observed after exposure of a cell to various damaging factors [12], which include UV radiation, changes in $\mathrm{pH}$ and osmolality, carbon or nitrogen deficits, ethanol, heavy metals, antibiotics, oxidative stress, and viral infections [13, 14].

The role of HSP70 is to prevent the damage of proteins that could lead to their degradation. Damaged proteins are important for proper functioning of cells which cannot be repaired by heat shock proteins. These cells are usually "labelled" by chaperones with ubiquitin and lead to the proteasomal death pathway. Mass degradation of cell proteins in proteasomes is the signal of death through apoptosis.

The aim of the study is to show the reactions of cell stress markers in rat kidney cells that were subjected to L-arginine treatment: a cell responds to the threat by producing a variety of factors, including proteins whose aim is to protect it from the damage. Cellular proteins and genetic material contained in nuclear DNA are mainly vulnerable to the damage that leads to cell death. The first cell response to the damage of DNA is overproduction of the $p-53$ protein (the guardian of the genome), whose task is to stop the cell cycle, thereby enabling repairs.

A cell reacts to the factors that damage cellular proteins by overproduction of heat shock proteins, e.g. small HSPs, HSP40, HSP60, HSP70, HSP90, and HSP110. The most sensitive of these proteins is HSP70 [14]. Its overproduction in the cell is stimu- lated even by environmental pollution [8]. It is possible to detect even the earliest signs of cell stress because of choosing this protein. It is known from the literature that NO depending on the dose protects the cell or causes oxidative stress.

Other heat shock proteins such as HSP 60 and 65 are not such sensitive indicators of oxidative stress in particular that is expected in our work that investigates the effect of NO on cells.

Some authors have evaluated expression of HSP70 in many diseases. Sakai et al. in their experiment did not observe a significant increase of HSP70 expression in renal cell carcinoma [15]. Ugurlucan et al. found that diabetes mellitus causes aortic stiffness and this may contribute to the increase in mortality and morbidity associated with DM. The expression of HSP 70 may become a therapeutic target [16]. Bielecka-Dąbrowa et al. using as a method a literature review wrote that the role of HSPs in atherosclerosis is controversial. HSP60 probably acts as an autoantigen, while HSP70 is likely to be involved in cytoprotection [14].

Other authors concluded in their investigations that HSP70, because of its sensitivity, has been hailed as a biomarker of cellular stress, including oxidative stress and environmental sustainability in which the organism functions [8]. They described several mechanisms of an antiapoptotic action of HSP70. HSP70 decreases cell sensitivity to death signals such as TNF, monocytes, oxidative stress, ceramide, UV radiation, overproduction of caspase 3 and some chemotherapeutics.

In the present study, HSP70 reaction in renal cells of the healthy, control rats was not negative. The reaction was visible and it covered about $1.5 \%$ of the renal cell surface. The most probable cause of this phenomenon is an inability to eliminate all the environmental stressors the healthy rats were exposed to. Constantly increasing concentration of chaperones in cells of healthy animals is essential for proper protection of cell proteins - both newly synthesized and mature ones.

It was described by several researchers. Neuhofer et al. [17] studied the concentration of heat shock proteins in the renal papillae and demonstrated that in physiological conditions the renal papillary cells adapted to their hyperosmotic environment through the overproduction of HSP70.

In the present study, cells also tried to repair the damage and prevent apoptosis in a different way. An increase in the $p-53$ reaction indicates an attempt to repair the L-arginine damage.

$\mathrm{P}-53$ is thought to be the protein which plays a crucial role in coordination of the cell response to various factors, such as hypoxia, DNA damage, and heat shock $[18,19]$. During the action of a harmful factor, e.g. L-arginine, its concentration should increase. It was observed in the present study. The 
renal epithelial cells responded to L-arginine therapy by increasing the expression of HSP70 and p-53 proteins.

It might be a signal for researchers that cells are not in a good condition. It will be interesting to check if L-arginine induces apoptosis in renal tubular epithelial cells examined in the present study. It is going to be a subject of the author's future investigations.

\section{References}

1. Pedrycz A, Brzeski Z. L-arginine decreases heat shock protein 70 (marker of environmental stress) expression in kidney cells of rat foetuses during apoptosis - late effect of adriamycin action. Ann Agric Environ Med 2006; 13: 129-32.

2. Pedrycz A, Kot K, Olesiński I. Immunohistochemical evaluation of caspase 3 expression in rats' hepatocytes after l-arginine therapy. Bull Vet Inst Pulawy 2010; 54: 101-3.

3. Antczak A, Ciebiada M, Pietras T, Piotrowski WJ, Kurmanowska Z, Górski P. Exhaled eicosanoids and biomarkers of oxidative stress in exacerbation of chronic obstructive pulmonary disease. Arch Med Sci 2012; 8: 277-85.

4. Guicciardi M, Gores GJ. AIP1: a new player in TNF signaling. J Clin Invest 2003; 111: 1813-5.

5. Smith O. Cancer. Nota bene: the killer instinct of a $\mathrm{p}-53$ target. Science 2000; 290: 67-9.

6. Skowyra D, Żylicz, M. Heat-shock proteins. Postepy Biochem 1987; 33: 259-76.

7. Fikus M. Chaperones for biophysicist. Wiedza i Życie 2000; 4: 22-5.

8. Yoo J, Janz DM. Tissue-specyfic HSP70 levels and reproductive physiological responses in fishes inhabiting a metal-contaminated creek. Arch Environ Contam Toxicol 2003; 45: 110-20.

9. Rytlewski K, Olszanecki R, Korbut R, Zdebski Z. Effects of prolonged oral supplementation with l-arginine on blood pressure and nitric oxide synthesis in preeclampsia. Eur J Clin Invest 2005; 35: 32-7.

10. Furchgott RF. Endothelium-derived relaxing factor: discovery, early studies, and identification as nitric oxide. Biosci Rep 1999; 19: 235-51.

11. Eu JP, Liu L, Zeng M, Stamler JS. An apoptotic model for nitrosative stress. Biochemistry 2000; 39: 1040-7.

12. Ramaglia V, Harapa GM, White N, Buck LT. Bacterial infection and tissue-specific Hsp72, -73 and -90 expression in western painted turtles. Comp Biochem Physiol C Toxicol Pharmacol 2004; 138: 139-48.

13. Grudniak AM. The role of chaperones DnaK I DnaJ in creation of active protein complexes in Escherichia coli. Doctoral thesis 2004; Warsaw University.

14. Bielecka-Dabrowa A, Barylski M, Mikhailidis DP, Rysz J, Banach M. HSP 70 and atherosclerosis: protector or activator? Expert Opin Ther Targets 2009; 13: 307-17.

15. Sakai I, Miyake H, Takenaka A, Fujisawa M. Expression of potential molecular markers in renal cell carcinoma: impact on clinicopathological outcomes in patients undergoing radical nephrectomy. BJU Int 2009; 4: 942-6.

16. Ugurlucan M, Erer D, Kalko Y, et al. Aortic stiffness in diabetes mellitus: association with glutamine and heat shock protein 70 expression: a pilot study based on an experimental rodent model. Expert Opin Ther Targets 2009; 13: 267-74.

17. Neuhofer W, Holzapfel K, Fraec ML, Ouyang N, Lutz J, Beck FX. Chronic COX-2 inhibition reductases medullary
HSp 70 expression and induces papillar apoptosis in dehydrated rats. Kidney Int 2004; 65: 431-41.

18. Steele RJC, Thompson AM, Hall AP, Lane DP. The p53 tumor suppressor gene. Br J Surg 1998; 85: 1460-7.

19. Saxena N, Ansari KM, Kumar R, Dhawan A, Dwivedi PD, Das M. Patulin causes DNA damage leading to cell cycle arrest and apoptosis through modulation of Bax, $p(53)$ and $\mathrm{p}(21 / \mathrm{WAF} 1)$ proteins in skin of mice. Toxicol Appl Pharmacol 2009; 234: 192-201. 